\title{
Numerical Simulation of Pressure Fluctuation in High-pressure Common-rail Fuel Injection System
}

\author{
Yu Du ${ }^{1, ~ *, ~ C h e n g ~ Q i a n ², ~ Y u e ~ Z h a o ~}{ }^{2}$, Yukang Wang ${ }^{3}$, Peng Zhao ${ }^{4}$ \\ ${ }^{1}$ Pharmaceutical and Chemical Engineering Academy, Southeast University, Nanjing, China \\ ${ }^{2}$ Electronics and Computer Engineering Academy, Southeast University, Nanjing, China \\ ${ }^{3}$ Computer \& Software Academy, Nanjing University of Information Science \& Technology, Nanjing, China \\ ${ }^{4}$ Political and Law Academy, Shihezi University, Shihezi, China
}

\section{Email address:}

Duyu1998@126.com (Yu Du),1449737162@qq.com (Cheng Qian),582213947@qq.com (Yue Zhao), quinnyodel@foxmail.com (Yukang Wang), 1035409118@qq.com (Peng Zhao)

${ }^{*}$ Corresponding author

\section{To cite this article:}

Yu Du, Cheng Qian, Yue Zhao, Yukang Wang, Peng Zhao. Numerical Simulation of Pressure Fluctuation in High-pressure Common-rail Fuel Injection System. American Journal of Mechanical and Industrial Engineering. Vol. 4, No. 3, 2019, pp. 45-51.

doi: 10.11648/j.ajmie.20190403.12

Received: September 17, 2019; Accepted: September 28, 2019; Published: October 12, 2019

\begin{abstract}
In the past several years, the global diesel engine technology has made significant breakthroughs. The diesel engine has a good economy and power. In 20 years or so, the number of diesel vehicles will exceed the trend of gasoline engines. Diesel engine technology is also developing towards low pollution, low fuel consumption, and high power. To improve the performance of diesel engines, the key is to improve the conversion rate of internal energy to mechanical energy and combustion degrees. In the fuel injection system of diesel engines, a high-pressure common-rail with a large volume is often added between the plunger high-pressure fuel pump and the injector. Its function is to save fuel from the plunger fuel pump, to suppress the fluctuation of oil pressure, and to output high-pressure fuel by adjusting the characteristic parameters of the injector. Firstly, the physical model and mathematical model have been established, including the plunger pump, the high-pressure common rail, and the injector. After that, we use the modified Euler method to solve ordinary differential equations by MATLAB programming. Finally, the Optimized working strategies of plunger pump to inject diesel oil into high-pressure common rail have been obtained. In this high-pressure common rail system, cam of the plunger pump spin 1225.67 times a minute, and pressure relief valve is opened automatically when the pressure in high-pressure common-rail is over $103 \mathrm{MPa}$, so that the pressure in high-pressure common-rail is approximately stable at $100 \mathrm{MPa}$, and the fluctuation is small.
\end{abstract}

Keywords: High-Pressure Common Rail, Plunger Pump, Differential Equations

\section{Introduction}

In the past several years, the global diesel engine technology has made significant breakthroughs $[1,2]$. The diesel engine has a good economy and power. In 20 years or so, the number of diesel vehicles will exceed the trend of gasoline engines. Diesel engine technology is also developing towards low pollution, low fuel consumption, and high power. To improve the performance of diesel engines, the key is to improve the conversion rate of internal energy to mechanical energy and combustion degrees. Mechanical energy conversion requires proper injection time and compression ratio. Combustion requires better diesel atomization which needs higher injection pressure. Besides, diesel engines are required to have higher mechanical strength and quality and overcome many technical problems in fuel circuit design. Therefore, it is necessary to improve the fuel injection system to improve the performance of diesel engines.

Over the past decade, there have been a variety of technologies to improve injection pressure at home and abroad [3, 4]. Only high-pressure conventional rail technology is the most direct and easy to achieve this requirement. It cooperates with high precision injectors, 
ensuring the accuracy of injection time and meeting the needs of diesel engines, which shows many advantages in all aspects. Although the required injection time and quantity have been already known, another factor affecting the injection law is pressure waves [5]. Because the process of injection and emission of diesel oil is discontinuing, pressure fluctuation is inevitably formed in the rail tube, which directly affects injection time and quantity. Reducing pressure fluctuation in conventional rail tube is the main direction of diesel engine technology research at home and abroad.

The high-pressure common-rail electronic fuel injection system is similar to other electronic control systems [6], including sensors, electronic control units (ECU) and actuators. Specifically, it includes ECU, high-pressure fuel supply corn, conventional rail tube, electronic control ejector and various sensors. There are many sensors in the electronic control system, such as engine cam/crankshaft/throttle pedal position sensor, cooling water/fuel/intake temperature sensor and fuel pressure sensor. The ECU is analyzed by collecting various signals to feedback the running status of the diesel engine. Fuel is supplied to the fuel supply pump from the fuel tank through the fuel filter, pressurized in the plunger chamber, and then fed into the typical rail tube. According to the pressure regulation signal, the pressure in the conventional rail tube is controlled by pressure limitation and fuel input, and then the fuel is supplied to the electronic control ejector through the high-pressure fuel tube. According to the current operating conditions and the preset diesel engine, ECU is supplied to the electronic control ejector. Figure MAP determines the appropriate injection action and directs the solenoid valve to close. The final electronic control ejector injects fuel into the combustion chamber.

Herein, by analyzing the characteristics of the unsteady fluid, the mathematical model in the pipeline is simplified to a one-dimensional unsteady compressible fluid model. According to the equilibrium relationship between the flow rate at the inlet and outlet of the high-pressure common rail and the volume compression, the fuel continuity equation in the high-pressure common rail has been established. This ordinary differential equation and its initial condition are determined, and the fuel pressure in the high-pressure common rail changing varying time has been obtained. What is more, Optimized working strategies of a pump to inject diesel oil into high-pressure common rail have been obtained.

\section{Main Components of High-Pressure Common Rail Fuel Injection System}

\subsection{Common Rail}

In this work, the structure of the high-pressure common rail is simplified. As is shown in Figure 1, the length of the inner chamber of the high-pressure common rail is $500 \mathrm{~mm}$, the diameter of the inner chamber is $10 \mathrm{~mm}$, and the diameter of the orifice at the entrance $\mathrm{A}$ is $1.4 \mathrm{~mm}$. The oil supply time is controlled by the one-way valve switch. The one-way valve should be closed for $10 \mathrm{~ms}$ every time it is opened. The injector works ten times per second, and the injection time is $2.4 \mathrm{~ms}$.

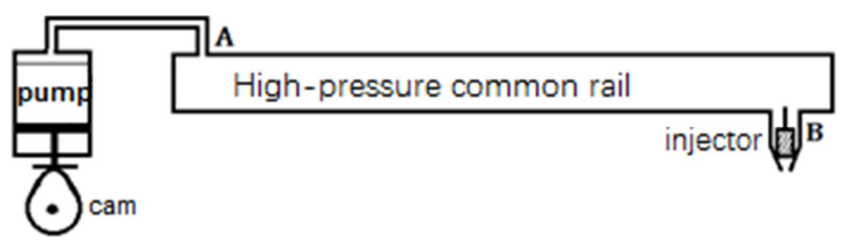

Figure 1. Schematic diagram of high-pressure common rail.

\subsection{Plunger Pump}

A high-pressure fuel pump affects the pressure in conventional rail tube by controlling the fuel quantity supplied to a standard rail tube and ensures that there is enough pressure in typical rail tube to ensure high fuel pressure during injection. There are no processing spiral grooves on the plunger of the high-pressure oil supply pump, and the oil supply is completely controlled by the speed of the cam. In the actual working process, the fuel in the high-pressure oil pipe A comes from the outlet of the plunger chamber of the high-pressure oil pump. The pressure process of the plunger of the high-pressure oil pump is shown in Figure 2.

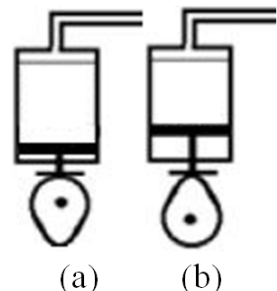

Figure 2. The process of cam driving plunger: (a) Lift minimum, (b) Lift maximum.

The cam drives the plunger to move up and down. When the plunger moves up, the fuel in the plunger chamber is compressed. When the pressure in the plunger chamber is higher than that in the high-pressure oil pipe, the plunger chamber and the one-way valve connected with the oil pipe open and the fuel enters the high-pressure oil pipe. The diameter of the plunger chamber is $5 \mathrm{~mm}$, and the residual volume of the plunger chamber is $20 \mathrm{~mm}^{3}$ when the plunger moves to the top dead point. When the plunger moves to the bottom dead point, the low-pressure fuel will fill the plunger chamber (including residual volume), and the pressure of the low-pressure fuel will be $0.5 \mathrm{MPa}$.

\subsection{Injector}

The electronically controlled injector is an important component of the high-pressure universal rail injection system. The parameters of injection characteristics, such as injection starting point, injection duration, and injection volume, are controlled and adjusted by solenoid valve. Common rail injector is similar to the injector structure indirect injection diesel engines, so there is no need to change the structure of cylinder head. Just clamp it on the cylinder head.

The nozzle structure of the injector is shown in Figure 3. 


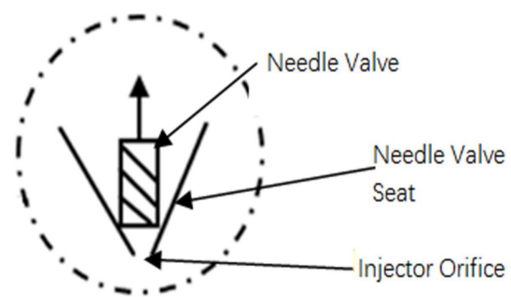

Figure 3. Schematic diagram of the needle valve.

The diameter of the needle valve is $2.5 \mathrm{~mm}$, the sealing seat is a cone with a half angle of 9 degrees, and the diameter of the bottom nozzle is $1.4 \mathrm{~mm}$. When the needle valve lift is 0 , the needle valve closes; when the needle valve lift is greater than 0 , the needle valve opens, and the fuel flows to the nozzle and sprays out through the nozzle.

\section{Establishment of Mathematical Model for High-Pressure Common Rail System}

\subsection{Fluid Continuity Equation in Plunger Pump}

A one-way valve is a connecting passage between the plunger chamber and high-pressure ordinary rail pipe. According to the flow process of fuel, the continuous equation of fuel in plunger chamber of fuel supply pump can be listed, which describes the equilibrium relation of fuel volume in piston Cavity during $t$ to $\mathrm{d} t$ :

$$
Q_{p}=Q_{V p}+Q_{p \rightarrow r}+Q_{p o l}
$$

Where $Q_{p}$ donates the volume of oil instantaneously injected into the plunger, i.e. geometric oil supply rate, $Q_{V p}$ donates the compression volume change rate of the plunger chamber, $Q_{\text {pol }}$ donates the flow from low-pressure oil passage and $Q_{p \rightarrow r}$ donates the flow to common rail tube.

If the plunger lift is donated by $h_{p}$ moreover, the diameter of piston is donated by $d_{p}$, the geometric oil supply rate can be obtained easily:

$$
Q_{p}=\frac{\pi}{4} d_{p}^{2} \frac{d h_{p}}{d t}
$$

Figure 4 illustrates the shape of cam, i.e., plunger lift $h_{p}$ :

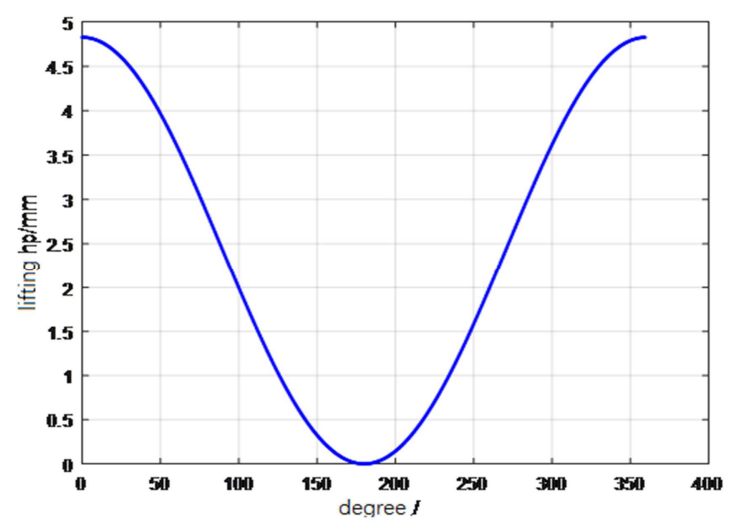

Figure 4. The degrees of cam with plunge lift.
Providing that the centralized volume of the plunger chamber is $V_{p}$, the plunger chamber pressure is $P_{p}$ and the modulus of elasticity is $E, Q_{V p}$ can be described as:

$$
Q_{V p}=\frac{V_{p}}{E} \cdot \frac{d P_{p}}{d t}
$$

We use step function $\xi$ to control the switch of the one-way valve at the oil inlet. When the pressure in the plunger is more significant than that in the high-pressure ordinary rail pipe, the one-way valve opens.

$$
\xi=\left\{\begin{array}{l}
1, P_{p} \geq P_{r} \\
0, P_{p}<P_{r}
\end{array}\right.
$$

Thus, the flow rate of the plunger chamber to the high-pressure common rail tube through a one-way valve can be calculated by equation (5).

$$
Q_{p \rightarrow r}=\xi \mu_{p r} F_{p r} \sqrt{\frac{2}{\rho}\left|P_{p}-P_{r}\right|}
$$

Where, $\mu_{p r} F_{p r}$ donates active area from plunger chamber to high-pressure common rail tubing.

A step function is used to control the opening and closing of a one-way valve at the entrance of the low-pressure fuel to the plunger. When the pressure in the plunger is less than that in the plunger, the one-way valve opens, i.e.

$$
\varsigma=\left\{\begin{array}{c}
0, P_{p} \geq P_{o l} \\
-1, P_{p}<P_{o l}
\end{array}\right.
$$

Thus, the flow rate from the low-pressure tube to the plunger chamber through a one-way valve can be calculated by equation (7).

$$
Q_{p o l}=\varsigma \mu_{p o} F_{p o} \sqrt{\frac{2}{\rho}\left|P_{p}-P_{o l}\right|}
$$

All in all, the fluid continuity equation in plunger pump is:

$$
\frac{d P_{p}}{d t}=\frac{E}{V_{p}}\left(\frac{\pi}{4} d_{p}^{2}-\xi \mu_{p r} F_{p r} \sqrt{\frac{2}{\rho}\left|P_{p}-P_{r}\right|}-\varsigma \mu_{p o} F_{p o} \sqrt{\frac{2}{\rho}\left|P_{p}-P_{o l}\right|}\right)
$$

\subsection{Mathematical Model of Common Rail Tube}

Continuous equation of common rail is:

$$
\frac{V_{p}}{E} \cdot \frac{d P_{p}}{d t}=\sum U_{\text {in }} A_{\text {in }}-\sum U_{\text {out }} A_{\text {out }}
$$

Where, $P_{p}$ donates the pressure in typical rail tube, $V_{p}$ donates the volume of common rail. $U$ donated the running speed of oil inflow and outflow ordinary rail pipe respectively, and $A$ donates the section area of entrance and exit respectively.

In summary, the continuous equation of common rail is:

$$
\frac{V_{r}}{E} \cdot \frac{d P_{r}}{d t}=\xi \mu_{p r} F_{p r} \sqrt{\frac{2}{\rho}\left|P_{p}-P_{r}\right|}-Q_{\text {out }}
$$

\subsection{Mathematical Model of the Needle Valve}

The injector used in this paper mainly includes nozzle, 
needle valve, and sealing seat. The lifting and falling of needle valve control the opening and closing of injection. Before the needle valve is lifted, the high-pressure oil pipe is connected with the needle valve chamber. After the needle valve is lifted, the high-pressure oil pipe communicates with the injection nozzle around the needle valve and discharges fuel outward. Continuous equation of internal combustion oil in nozzle chamber:

$$
Q_{r \rightarrow N}=F_{N} \frac{d h_{N}}{d t}+\frac{V_{r}}{E} \cdot \frac{d P_{r}}{d t}+\frac{d V_{N}}{d t}
$$

Where, $h_{N}$ donates needle valve lift, $F_{N}$ donates the section area of the needle valve.

Figure 5 illustrates the needle valve lift $h_{N}$ changing with time:

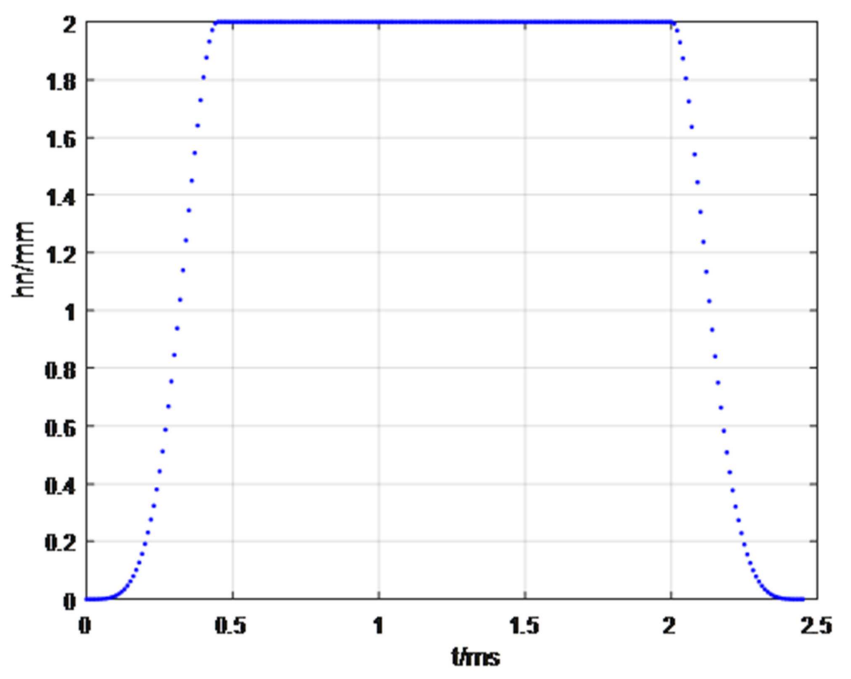

Figure 5. The needle valve lift with time in one cycle.

In order to simplify the model, we neglect the resistance loss and local pressure loss along the high-pressure common rail connecting with the nozzle chamber. The boundary condition is adopted:

$$
P_{r}=P_{N}
$$

Providing that the external pressure of the nozzle is $P_{0}$, export flow can be obtained easily:

$$
Q_{\text {out }}=\mu_{N 0} F_{N} \sqrt{\frac{2}{\rho}\left|P_{N}-P_{0}\right|}
$$

Considering the flow cross-section changes with the needle

$$
P_{p n+1}=P_{p n}+h \frac{E}{V_{p}}\left(\frac{\pi}{4} d_{p}^{2}-\xi \mu_{p r} F_{p r} \sqrt{\frac{2}{\rho}\left|P_{p}-P_{r}\right|}-\varsigma \mu_{p o} F_{p o} \sqrt{\frac{2}{\rho}\left|P_{p}-P_{o l}\right|}\right)
$$

Where the pressure of low-pressure fuel is $P_{o l}=0.5 \mathrm{MPa}$, which is the boundary condition.

For the high-pressure common rail, according to equation (10), the difference is:

$$
P_{r n+1}=P_{r n}
$$

valve lift $h_{N}$, which is varies with time. Providing that the radium of the needle valve is $1.25 \mathrm{~mm}$ before the needle valve is lifted, the flow cross-section is zero and $\mathrm{R}$ equals with the diameter of needle valve. During the lifting process, $\mathrm{R}$ increases gradually. The ring formed between the needle valve and the circle formed by the radius of $\mathrm{R}$ (see red ring part Figure 6) increases continuously, and the flow cross-section is the red part. Along with the continuing lifting of the needle, the ring area will become more significant than that of the bottom of nozzle (see the blue part in Figure 6), and the flow cross-section is the red part changes to blue part. In this model, the smaller values of nozzle bottom and annular area are taken.

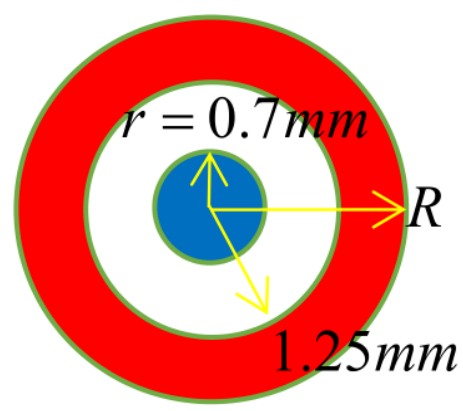

Figure 6. Schematic diagram of the needle valve.

Thus, the flow cross-section of needle valve can be described as:

$$
F_{N}=\left\{\begin{array}{c}
\pi r^{2}, 1.25<R \leq 1.4327 \\
\pi\left(R^{2}-1.25^{2}\right), 1.4327<R \leq 1.5716
\end{array}\right.
$$

\section{Stabling the Fluctuations of Pressure in the Common Rail}

According to above differential equations, the relationship between the pressure in common rail tube and time can be obtained theoretically. Herein, we use modified Euler method to solve ordinary differential equations. Firstly, we need to discrete these ordinary differential equations.

\subsection{Establishment of Difference Equations Model in Common Rail System}

For high-pressure pumps, according to equation (8), the difference equation is: 
chamber are neglected, i.e. $P_{r}=P_{N}$, so that the outlet flow can be obtained directly:

$$
Q_{\text {out }}=\mu_{N 0} F_{N} \sqrt{\frac{2}{\rho}\left|P_{N}-P_{0}\right|}
$$

Assuming that the external pressure $P_{0}$ is $0.1 \mathrm{MPa}$ as the other boundary condition. These differential equations can be easily solved by modified Euler method.

The algorithm is realized by programming in MATLAB. If the speed of the cam in the piston pump is $1230.2 \mathrm{r} / \mathrm{min}$, the curve illustrating the pressure in common rail tube changing with time within the first 10s is shown in Figure 7.

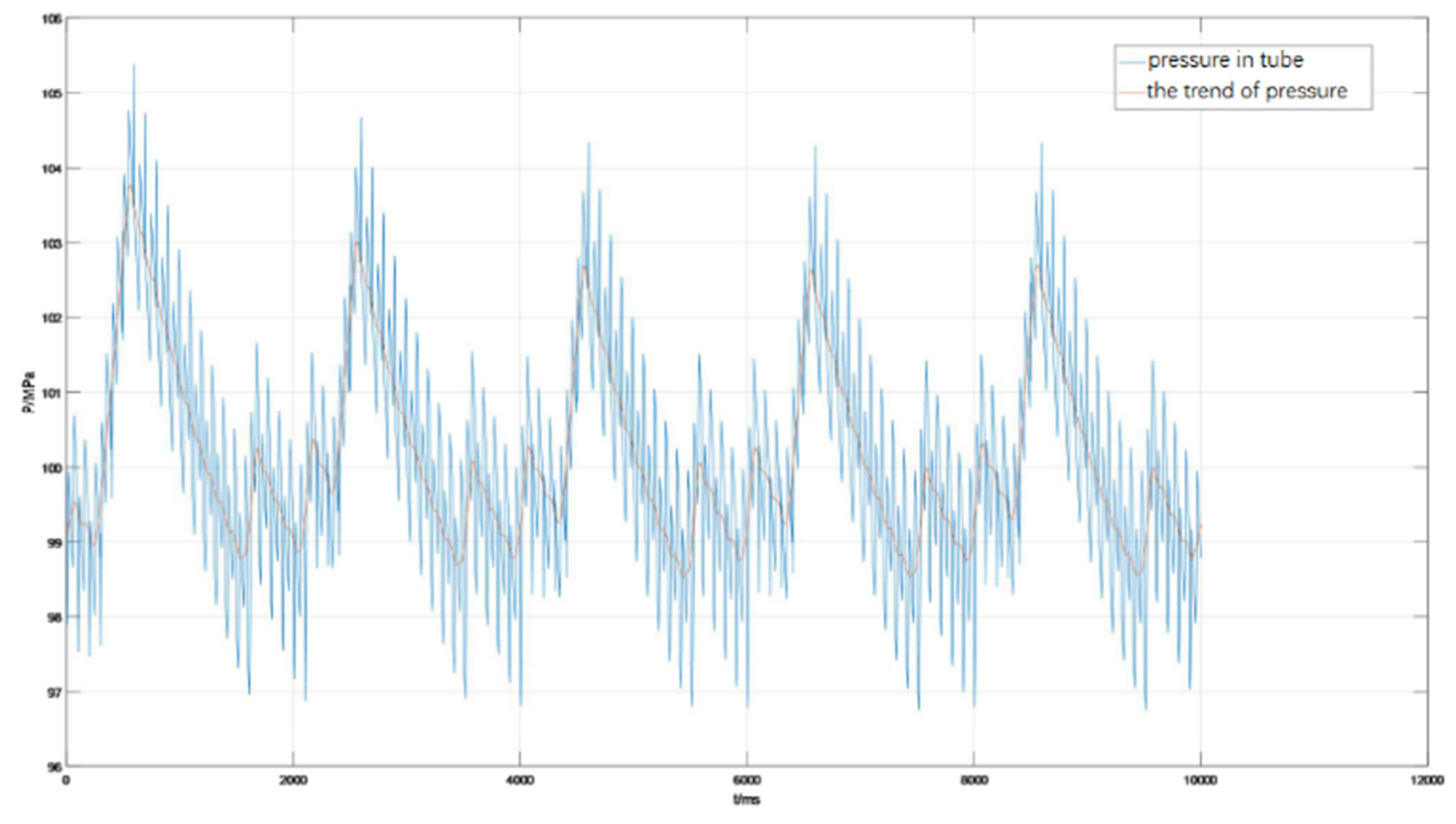

Figure 7. Pressure changing with time.

\subsection{Result and Discussions}

As is shown in Figure 5, with high-speed reciprocating operation of high-pressure piston pump and injector, the pressure presents a dense zigzag change. In order to better reflect the trend of pressure change, the "smooth ()" function in MATLAB is used to denoise the image (see the orange curve in Figure 5). In addition to the dense sawtooth change of pressure, there is a sizeable periodic fluctuation in a long time. The period is about $\mathrm{s} 2$, which is much larger than the movement period of high-pressure oil pump and injector. It may originate from step function $\xi$, which controls the switch of the one-way valve at the oil inlet. If the pressure in pump is lower than that in common rail tube for a while, the one-way would continuously close, which leads to a sharp drop in pressure.

\subsubsection{High-Pressure Common Rail System with Two Nozzles}

In a further study, we simulate the pressure fluctuation in high-pressure common rail system with two injectors (see Figure 8 , where $\mathrm{B}$ and $\mathrm{C}$ represent the tow nozzles respectively, and $\mathrm{D}$ represents the pressure relief valve).

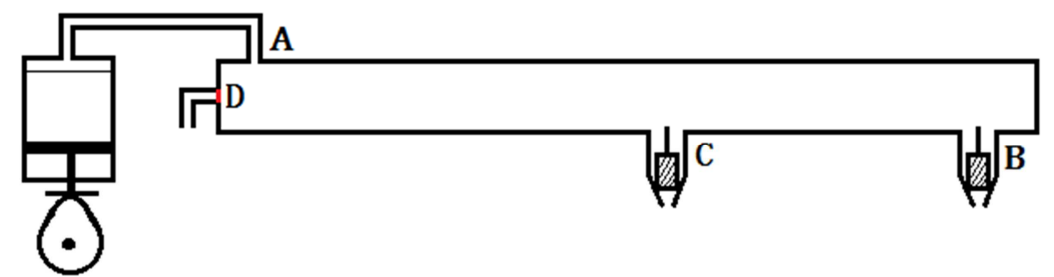

Figure 8. Schematic diagram of high-pressure common rail with pressure relief valve and two nozzles.

Firstly, we shorten the opening time of each injector and adjust the injection time interval between the two injectors, so that the pressure fluctuation in the high-pressure tubing is reduced and more stable. If the speed of the cam in the piston pump is $1225.67 \mathrm{r} / \mathrm{min}$, the curve illustrating the pressure in common rail tube changing with time within the first $20 \mathrm{~s}$ is shown in Figure 9. 


\subsubsection{Add a Pressure Relief Valve}

After adding a nozzle, according to the image of pressure fluctuation (Figure 9), the pressure in the whole high-pressure tubing is unstable due to the excessive pressure peaks in some moments. Installing a one-way pressure relief valve on the high-pressure tubing can effectively avoid excessive pressure in the high-pressure tubing. When the pressure in the high-pressure tubing is higher than $103 \mathrm{MPa}$, the pressure relief valve is opened to reduce the pressure in the high-pressure tubing and avoid the occurrence of excessive pressure.

After installing a relief valve, when the speed of the cam in the piston pump is $1225.67 \mathrm{r} / \mathrm{min}$, the curve illustrating the pressure in common rail tube changing with time within the first 20s is shown in Figure 10.

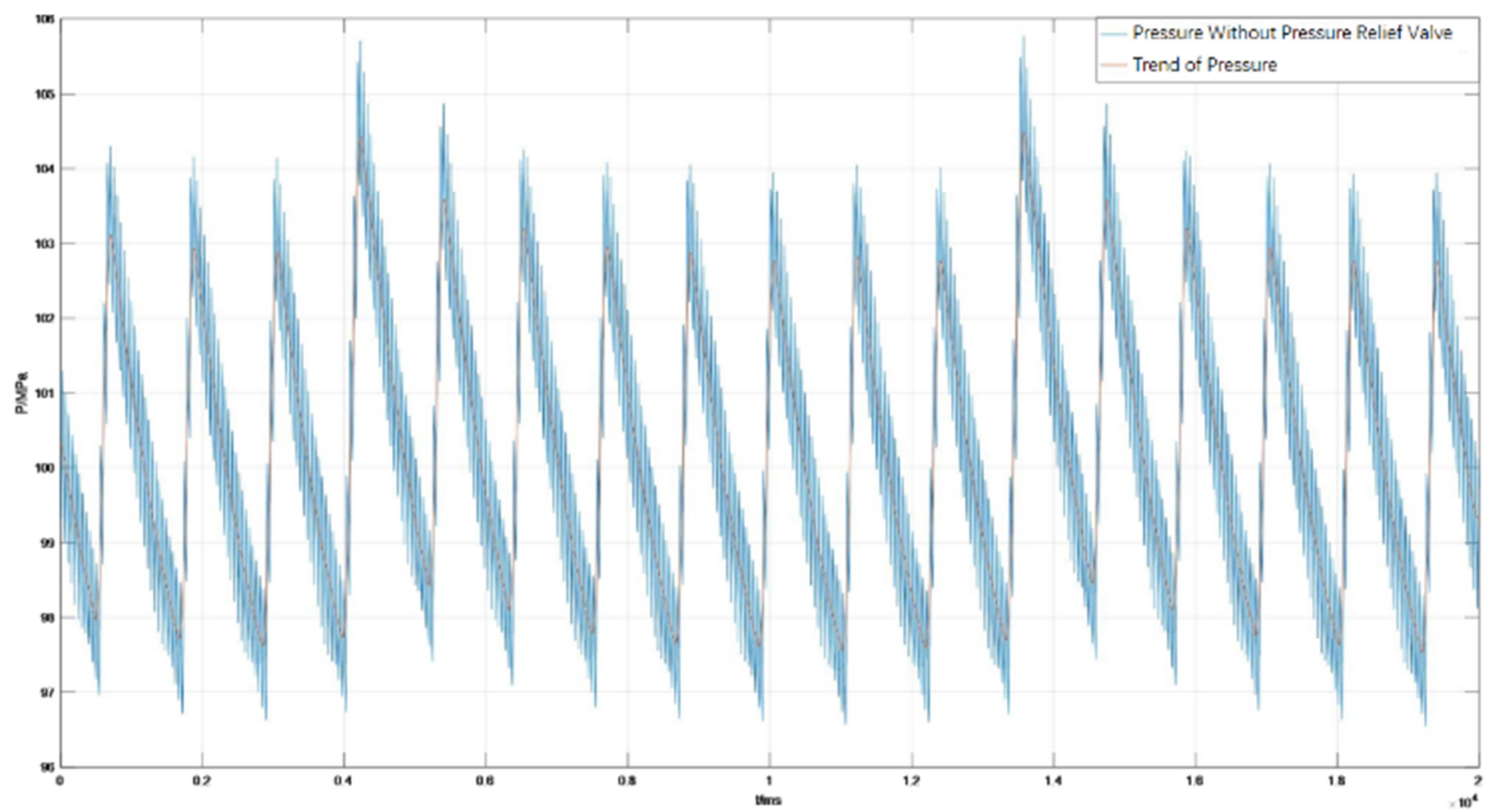

Figure 9. Pressure changing with time with two nozzles.

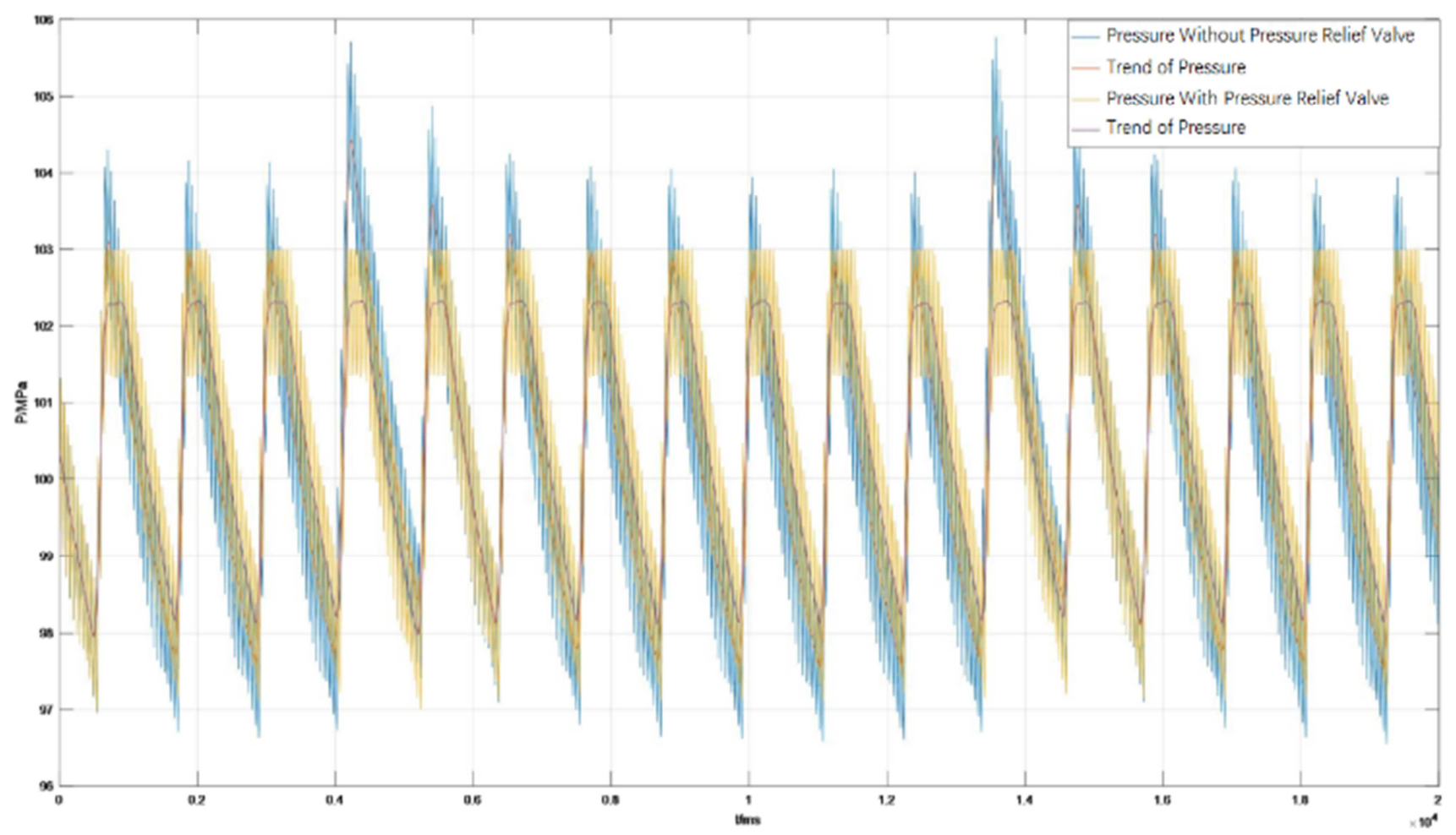

Figure 10. Pressure changing with adding a pressure relief valve. 
It can be seen from the image that the pressure relief valve successfully controls the pressure in the high-pressure tubing below $103 \mathrm{MPa}$, and makes the pressure in the high-pressure tubing more stable.

\section{Conclusion}

Based on the high-pressure universal rail fuel injection system, the structure and working principle of the fuel injection system are introduced. According to the mathematical model and physical model, the simulation model of the electronic control fuel injection system is built by MATLAB programming to simulate and calculate. The simulation object is divided into three parts: a high-pressure fuel supply pump, high-pressure ordinary rail pipe, and injector. The influence of working parameters and structural parameters of each part on the injection process of the system is discussed and analyzed, which can provide reference for future experiments and applications, reduce blindness and significantly shorten the injection system of high-pressure common rail. Workload and cycle of research.

The conclusions are as follows. When the two nozzles are interlaced, the opening time of the injection needle valve is reduced to half of the original one, which can make the high-pressure fuel ejection flow more uniform. Set the speed to $1225.67 \mathrm{r} / \mathrm{min}$. When the pressure sensor detects that the pressure in the high-pressure tubing is higher than $103 \mathrm{MPa}$, the pressure relief valve opens. This method can effectively control the pressure stability of around $100 \mathrm{MPa}$. The average pressure of the first $20 \mathrm{~s}$ was $100.5099 \mathrm{MPa}$, and the mean square deviation within the first $20 \mathrm{~s}$ with $100 \mathrm{MPa}$ is 2.0176 . It can be seen from the image that the pressure relief valve successfully controls the pressure in the high-pressure tubing below MPa 102, and makes the pressure in the high-pressure tubing more stable.

\section{Acknowledgements}

This work was supported by a mathematical modeling coaching group at Southeast University Chenxian College. Thanks to all teachers providing guidance in the process of mathematical modeling. Thanks for the Chinese mathematical contest in modeling organizing committee.

\section{References}

[1] Common Rail injection developed for Hino engine. Paul Johnson. High Speed Diesel \& Drives. 1996.
[2] New Caterpillar Fuel System Aims to Expand Markets Applications. Mike O. High Speed Diesel \& Drives. 1995.

[3] A Hydro-Mechanical Simulation of Diesel Fuel Injection System. David R. Sobel, et al. SAE 870432.

[4] Development of J-Series Engine and Adoption of Common-Rail Fuel Injection System. Shin Endo, Yusuke Adachi, Yoshiki Ihara et al. SAEPaper970818.

[5] Lin Hong Bao, Research of High Pressure Common Rail Pipe Parameters on the Effects of Cavity Pressure Fluctuations. D. Chang'an University, Xi'an, China. 10710-2012525026

[6] Z. Zhao, J. Wang and Y. Liu, "User Electricity Behavior Analysis Based on K-Means Plus Clustering Algorithm," 2017 International Conference on Computer Technology, Electronics and Communication (ICCTEC), Dalian, China, 2017, pp. 484-487. doi: 10.1109/ICCTEC.2017.00111

[7] Bo Q, Yong Z, Guo D. Study on seal performance of injector nozzle in high-pressure common rail injection system $[\mathrm{J}]$. Journal of the Brazilian Society of Mechanical Sciences \& Engineering, 2018, 40 (2): 97.

[8] Zhang K, Huang X, Xie Z, et al. Design and optimization of a novel electrically controlled high pressure fuel injection system for heavy fuel aircraft piston engine $[\mathrm{J}]$. Chinese Journal of Aeronautics, 2018, 31 (9): 127-135.

[9] Lei Z, Liu Z, Yang K, et al. Experimental study on spray characteristics of ultra high pressure common rail system for marine diesel engine [J]. Journal of Huazhong University of Science \& Technology, 2018, 46 (3): 85-90.

[10] L. Yi and W. Yi, "Decision Tree Model in the Diagnosis of Breast Cancer," 2017 International Conference on Computer Technology, Electronics and Communication (ICCTEC), Dalian, China, 2017, pp. 176-179. doi: 10.1109/ICCTEC.2017.00046.

[11] Ling W, Li G, Xu C L, et al. THE INVESTIGATION OF GEOMETRIC PARAMETERS ON THE INJECTION CHARACTERISTIC OF THE HIGH PRESSURE COMMON-RAIL INJECTOR [J]. Journal of Engineering for Gas Turbines and Power, 2018.

[12] Ihme M, Ma P C, Bravo L. Computational Modeling and Analysis of Diesel-fuel Injection and Autoignition at Transcritical Conditions [J]. 2018.

[13] Tadokoro T, Kotari M, Ohtaka T, et al. Pressure Rises Due to Arc under Insulating Oil in Closed Vessel-Pressure Fluctuation of Depth Direction in Oil [J]. Electrical Engineering in Japan, 2018, 202 (2): 43-53.

[14] Zhang Yanjun, Yang Xiaodong, Liu Yi, Zheng Dayuan, Bi Shujun. Research on the Frame of Intelligent Inspection Platform Based on Spatio-temporal Data. Computer \& Digital Engineering [J], 2019, 47 (03): 616-619+637. 